\title{
Academic Spin-Offs at Different Ages: A Case Study I n Search of Key Obstacles to Growth
}

\author{
Marina van Geenhuizen* and Danny P. Soetanto** \\ Faculty of Technology, Policy and Management** \\ Delft University of Technology, Delft, The Netherlands. \\ E-mail corresponding author: $\underline{\text { m.s.vangeenhuizen@tudelft.nl }}$
}

\begin{abstract}
Support to enhance early growth of academic spin-off firms is at the core of many economic policies. Efficiency of this support has been recently questioned due to slow growth of spinoff firms in various European countries. However, despite many studies to improve support, there is virtually no empirical insight into resistance of obstacles that constrain growth over time and how this differs between distinct types of spin-offs. This article explores the incidence and nature of obstacles to growth in a cross-section and longitudinal approach, and uses Delft University of Technology (the Netherlands) as a case study. We find evidence that (1) the overall ability to overcome obstacles decreases at the age of four, most probably reflecting the rise of the so-called credibility juncture, and that (2) highly innovative spin-offs start with an accumulation of obstacles but move relatively quickly to sustainable growth. The paper concludes with recommendations for the design of new (renewed) incubation policies and for further research.
\end{abstract}

Key words: Academic spin-off firms, Obstacles, Age, Stage-based development, Critical junctures, Incubation programs

\section{Setting the Scene}

Fostering spin-off firms, within the aim of commercialization of university research, is today at the core of many national and local economic policies, including Europe, North America and increasingly Asia (Kroll and Liefner 2008; Rasmussen 2008; Shane 2004). A major reason for the policy attention in Europe lies in what is called the "European paradox", i.e. the contradictory situation of a high level of publicly financed knowledge production at universities and research institutes and a limited wealth creation using the knowledge (European Commission 1995; Wright et al. 2007).

Academic spin-off firms are seen as performing a range of important functions, including a vehicle for technology transfer and technology commercialization, a way to produce direct income for universities (rent of laboratories), a source of employment, a way to strengthen the relationships with the local business community and, particularly in depressed areas, a way to 
contribute to restructuring regional economies (e.g., Charles 2003; Van Geenhuizen et al. 2005; Mian 1997; Perez and Sanchez 2003; Roberts and Malone 1996). Following Pirnay et al. (2003) academic spin-offs are defined as a particular set of spin-offs, created for the purpose of commercially exploiting a new technology or research results developed within a university. In addition, the firm founders have their origins in the universities and the transfer of knowledge from university to company is direct.

We refer in this study to two debates: a policy-oriented debate on efficiency of incubation support and role of differentiation of spin-offs herein, and a theoretical debate concerning age-pattern of obstacles to growth with a focus on advantages of first-mover firms. Many universities employ incubators as central buildings supplying relatively cheap and flexible accommodation, including shared services and access to pre-seed capital, as well as programs for improving the entrepreneurial capabilities of founders/managers. In addition, various universities without a central incubator building supply incubation support to spin-offs located at distributed places on-campus and off-campus. In the past few years, a critical debate has emerged on academic incubation programs focusing on efficiency of support measures and the role of heterogeneity of spin-off firms in limiting efficiency (Mustar et al. 2007; Wright et al. 2007; Wright 2008). The issue of efficiency has been raised because academic spin-off firms tend to remain relatively small and fail to grow, as is witnessed in the European Union with most spin-offs not larger than 10 employees after six years of existence. This growth pattern suggests that large numbers of spin-offs remain struggling with particular obstacles over a long time span. The role of heterogeneity of spin-off firms is addressed because of different needs due to diverse experience before start and a different involvement in R\&D, manufacturing and services, etc., leading to different demand for incubation support (e.g. Druilhe and Garnsey 2004; Heirman and Clarysse 2004; Mangematin et al. 2003).

Despite many studies on ways to develop and improve incubation programs (e.g. Aernoudt 2004; Clarysse et al. 2005; Rothaermel and Thursby 2005) evidence on how academic spin-offs' needs for resources change with age in a longitudinal way is scarce, but attention is increasing (e.g. McAdam and McAdam 2008; Reid and Garnsey 1998; Vohora et al. 2004). In this study, we apply resource-based views and stage-based models of firm growth, allowing a focus on changing needs for resources in early growth and ways through which spin-offs can gain missing resources. In a stage-based model of early growth, spin-off firms follow various stages and face critical junctures (thresholds) in terms of resources needed before reaching next growth stage (Vohora et al. 2004). Theory on first-mover advantages provides sufficient ground to assume different age-patterns of critical junctures for 
highly innovative spin-offs compared with other ones (Lieberman and Montgomery 1998). This theory seems not consistent in that first-movers are seen as enjoying advantages of superior resources but also suffering from technological and market uncertainty, and from large efforts in learning. Empirical evidence from medium-sized (large) samples using a longitudinal approach on ages of critical thresholds and how this differs for various classes of spin-offs, is however absent.

In response to the empirical challenge of a longitudinal study and of the theoretical debate on critical thresholds and first-mover advantages, the goal of this study is to gain knowledge about the nature and age of obstacles that prevent growth during the early years of spin-offs, and about thresholds and first-mover advantages for highly innovative spin-offs compared to other spin-offs. More precise, we address the following questions: 1) How does the pattern of obstacles change by age? 1a) What is the nature of obstacles at different ages? 1b) Which obstacles are most difficult to overcome? 2) To what extent is the age-pattern of obstacles different for highly innovative spin-offs compared to other spin-offs and is this connected with different needs for support? 3) When do spin-offs arrive at particular thresholds? And, 4) what may be the implications of the research results for the kinds of support needed? If these issues and questions can be answered using the resource-based perspective and a medium-sized sample of academic spin-off firms then there will be an opportunity to make a twofold contribution to knowledge. First, stage-based models of growth for academic spin-off firms and for different segments of them will be clarified and extended, particularly with age at which critical thresholds occur. Secondly, stakeholders involved in the fostering of spin-offs will have a clearer understanding of how to ensure that appropriate support is made available for spin-offs at different ages leading to more efficient results.

We build on a previous study based on cross-section data of age-patterns of obstacles (Soetanto and Van Geenhuizen 2007) by adding insights gained from a longitudinal analysis. The case study we use is Delft University of Technology. This university adopted an incubation program of distributed support in 1998. We make a particular distinction between highly innovative spin-offs and other ones, in that highly innovative spin-offs produce a product (service) "new to the sector" or new as a "breakthrough" using relatively high R\&D expenditure. Note that we are not attempting to explore a causal relation exclusively between age (or stage), innovation intensity and spin-offs' obstacles, because the presence of obstacles is multi-causal in background (e.g. Niosi 2006). The paper is structured as follows. First, we reflect on the resource-based perspective on early growth. A discussion of the methodology follows, highlighting the combination of a survey and in-depth interviews (quantitative and 
qualitative data), the use of both cross-sectional and retrospective analysis, and various measurement issues. Next, we examine the results, i.e. the nature of obstacles to growth and how these obstacles tend to change with age, indicating the occurrence of critical junctures, with a focus on highly innovative spin-offs. In a final section, the results are discussed in a broader context, and some future research and policy implications are indicated.

\section{Development Stages and Resource-based Perspective}

Firms develop or acquire resources as input and convert these into products or services for which revenue can be obtained (e.g. Barney 1991; Barney 2006). According to resourcebased views, firms are collections of resources and capabilities that behave differently dependent upon the level of uniqueness of resources and difficulty to imitate them. By nature, academic spin-off firms are in short of resources and the literature most often mentions a lack of investment capital and a lack of non-technical knowledge and skills (e.g., Locket et al. 2005; Reid and Garnsey 1998). Accordingly, to seize opportunities in early years, spin-offs need to organize access to these resources with success critically depending on presence of key suppliers in their environment, such as customers and investors, and on capabilities in networking with them (e.g., Hackett and Dilts 2004; Hoang and Antoncic 2003; Walter et al. 2006). In fact, the incubator (or incubation organization) acts as mediator or a direct supplier of resources without substantial costs (Rothaermel and Thursby 2005).

Using the resource-based perspective, obstacles can be perceived as poor or nonavailability of key resources at the time spin-offs need these resources. Obstacles may include shortage in management skills, shortage in market knowledge and marketing skills to access the market, and financial obstacles such as lack of cash flow and lack of investment capital (e.g. Blaydon et al. 1999; Oakey 2003; Roberts 1991). Obstacles may thus refer directly to resources but also to capabilities in gaining them over time. In addition, some situations may hinder spin-offs in utilizing available resources, like the bureaucracy faced in obtaining permits in a timely manner. While the resource-based view provides insight into academic spin-offs performance at a point in time, there is a paucity of evidence on the impact of resources or lack of them with increasing firm age or progress in the lifecycle (e.g. McAdam and McAdam 2008). Theory on lifecycle development provides insight into how small firms adapt to effectively utilize scarce resources in pursuit of growth and this view is consistent with the above-indicated resource-based perspective. The most representative one of lifecycle models - the Greiner model (1998) - suggests periods of incremental growth and crises-based growth, and postulates that firms go through five stages requiring appropriate strategies and 
structures to achieve sustained growth. Reid and Garnsey (1998) explicitly connected stages in ways of achieving resources (access, mobilization and generation) with needs for particular resources, including financial, physical, informational and relational resources. Accordingly, different needs for resources and modes to access them lead to different growth paths of spinoffs, i.e. early failure or steady growth, followed by outcomes like growth reinforcement, stability (eventually oscillation) and growth reversal. To deal with this dynamic growth, entrepreneurs need to be able to assess and satisfy their resource requirements as accurately as possible because they may gain a disproportional benefit if they meet critical requirements at the right point in time. A lack of this capability can cause a spin-off to stop growing, either because it enters a relatively steady phase or because it falls back to a previous stage (Reid and Garnsey, 1998).

More recently, Vohora et al. (2004) presented a model that puts explicit emphasis on important lack of resources in so-called "critical junctures" (or thresholds) at the interstices between development phases. This conforms to the earlier approach by Kazanjian and Drain (1989) to address dominant problems arising along the development path of new technologybased firms. According to Vohora et al. 2004, next phase cannot be reached without overcoming each of the four junctures, i.e. opportunity recognition, entrepreneurial commitment, credibility and sustainable returns. Three junctures seem to be important for our study as an empirical analysis of spin-offs after the establishment of it as a firm. We summarize them as follows (e.g. McAdam and McAdam 2008; Reid and Garnsey 1998; Vohora et al. 2004). The threshold of entrepreneurial commitment refers to the situation in which the entrepreneur is emotionally, financially and practically not sufficiently committed to lead the young firm full-time through the start-up phase, due to human capital deficiencies in the academic scientist (e.g. shortage of management skills and business foresight) and a constraining culture at university. The last situation may happen when universities allocate insufficient resources and incentives to academics in aligning the process of start-up and early growth making the decision for staff members to be fully engaged in the spin-off a difficult one. The threshold of credibility refers to the establishment of transactions with potential customers and to accessing resources from suppliers and (key) financers like venture capitalists. This threshold originates in the belief of taking high-risks if involved with young and small spin-offs. Credibility problems arise from a natural progression in independence of spin-off firms from the incubator management and move to mobilization and generation of resources. The threshold of sustainable returns refers to the ability to continuously reconfigure existing resources and weaknesses at hand into strength and opportunities, thereby 
creating sustainable returns. This ability requires organizational and managerial qualities of the entrepreneur (entrepreneurial team), like in developing appropriate coordination of productive activities and in delegation of tasks to employees or network partners.

Theory indicates various differences in resources availability between highly innovative firms (particularly first-movers) and other firms. Lieberman and Montgomery (1998) mention the following superior resources for first-movers: prime physical locations, a protected technology position (by patents), and monopoly in the market, eventually through a superior brand and product specificities causing "shifting costs" for customers. At the same time, they stress that first-movers may miss the best resources because these are obscured by technological and market uncertainties. By contrast, they mention that first-movers may gain a head start in achieving key capabilities and competencies through learning curve advantages. Other researchers, however, stress the ease of learning by follower-firms, particularly on consumer preferences and positioning in the market derived from first-mover experience (e.g. Kerin et al., 1992; Vakratsas et al. 2003). Given these ambiguous outcomes, we only make the assumption that first-movers attempt to overcome obstacles more quickly in early years because of the greater potential return of this strategy in a market monopoly.

\section{Methodological Aspects and Sample}

This study is based on a single case study, i.e., Delft University of Technology in Delft, the Netherlands. The in-depth character of the study, producing rich information on the phenomena at hand in a real-life context derived from both quantitative and qualitative data, justifies the single-case study design (Yin 1991). Results from this case study may yield new insights that are relevant beyond the local context of this particular university, for those situations in which major structuring factors, like the national innovation system (perceptions of entrepreneurship) and local incubation policies, are similar to the case study.

The size of the selected sample of spin-off firms in Delft is 78 and is derived from the following delineation: established in the years from 1994 to 2003, supported by the university in a relatively weak (low profile) support program from 1998 (or prior to this program) and located in Delft at the time of the survey (Note 1). Due to a response rate of $73.4 \%$ the actual sample size achieved was 58. Data were derived from a questionnaire-based survey and 15 additional in-depth interviews in 2003/2004 with entrepreneurs. The questionnaire included pre-defined answers as well as open questions. It focused on the identification of obstacles and the year in which these emerged/disappeared producing cross-sectional and longitudinal data, and on a limited number of background variables. The in-depth interviews encompassed five spin-off 
firms to pre-test the questionnaire and ten spin-off firms to collect in-depth information serving our understanding of the rise and disappearance of obstacles, like insight into credibility problems in the market and a related shortage of negotiation skills. In addition, we had several formal and informal meetings with the manager of the program at the university, we discussed results with different stakeholders in Delft in a meeting (university, municipality, representative of spin-offs, Chamber of Commerce) and made use of documentary data, all to improve the basis for our results. In other words, we used a combination of methodologies in investigating the same phenomenon (triangulation) (Denzin 1978).

To measure obstacles as "problematic situations in gaining resources", we used selfevaluation reported by the entrepreneurs. Obstacles could relate to the market, finance and management, accommodation and regulatory issues, etc. The obstacles reported are comparable in the sense that entrepreneurs have explicitly forwarded them in the frame of the research on growth and survival of their business. We measured age on the basis of the year of establishment of the firm in the sense of registration at the Chamber of Commerce. This has the disadvantage of disregarding the entrepreneurial activities - including preparation undertaken before registration, but it has the advantage to be a uniform event for all firms reflecting formal status. We used age in the analysis as one year-classes, as well as aggregations of year-classes. We have aggregated ages for two purposes, first to achieve agegroups of firms that are broadly similar in size and allow for comparison and statistical tests, and secondly, to achieve age-groups of firms that are different in facing obstacles to growth. Accordingly, we could describe various patterns of obstacle incidence with a focus on relatively high incidence (accumulation), and relatively high or low rates of decrease of obstacles with increasing age. This served to identify the occurrence of critical thresholds at particular ages.

To enable a comparative analysis of frequencies of obstacles we introduced two indicators, i.e. the obstacle incidence rate (OIR) and the obstacle reduction rate (ORR). OIR measures the frequency of obstacles per age (class) and corrects for the different numbers of spin-offs in age-classes (Soetanto and Van Geenhuizen 2007) (Appendix 1). We used both cross-sectional data and longitudinal data. Cross-sectional data cover obstacles at a point in time (time of the survey) for different ages in the sample of spin-off firms. Longitudinal data cover obstacles in each year in the life of spin-offs thereby providing the advantage that developments over time can be identified and understood at the individual level of the firms 
(note 2). Unlike most longitudinal research, using various observations based on real-time data, we used data derived retrospectively from the entrepreneurs.

Note that in interpretation of longitudinal patterns, we needed to consider potential influence of one major external factor, namely the downturn in economic development (early 2000s). Other external influences, like access to venture capital, legal issues concerning intellectual ownership, and the knowledge infrastructure in the region including the incubation policy of the university (O'Shea et al., 2008), remained stable during the years covered by our measurement of obstacles.

Using some of the above methodologies may be a source of bias. The self-evaluation method may cause some bias in the frequency of obstacles due to memory gap and other circumstances, like answering in a socially desirable way or with opportunistic intentions (improve own situation), and overestimation of obstacles due to negative business performance (e.g. Fowler, 2002). We may summarize our experience as follows. Memory gap: the questionnaire caused a sufficient awareness to prevent this gap. It includes a list of twelve predefined obstacles and open answers of obstacles, as well as an additional question on obstacles to stimulate memory by addressing ways of solving obstacles (Bradburn et al. 1987). Desirable and opportunistic answers: the questionnaire caused no serious under/overestimation because in our communication with the respondents we did not give attention to potential consequences of the study results; the data were also processed anonymously. Influence of negative business performance: we observed overestimation of obstacles among a few spin-offs that were directly threatened in daily business routines due to regulatory/legal issues, collapse of the entrepreneurial team, and a forced relocation. In addition, we need to mention that entrepreneurs might have responded differently in terms of magnitude of the obstacles, potentially causing slight obstacles (reported easily) to last for a long time. The interviews used to pre-test the questionnaire gave however no indication of entrepreneurs reporting mainly slight obstacles or a mix of slight and serious obstacles, rather serious ones. Overall, the strategy including pre-testing the questionnaire, using additional indepth interviews and other data-sources, served to increase validity of the results on obstacles. The pattern of "main obstacles" in our study, including market-related, financial and management obstacles, complies with findings in the Boston Area by Roberts (1991) with regard to market-related issues and financial issues. However, problems with personnel acquisition as experienced in the Boston Area are not common in Delft. Apparently, the modest size and growth of Delft's spin-offs does not cause scarcity of high technology personnel. The main obstacles observed in our study also comply with the ones indicated by 
Oakey (2003) and Vohora et al. (2004). According to the last study, the credibility threshold manifests itself in market-related and financial problems, whereas the threshold of sustainable returns manifests itself in management (coordination) problems. Aside from crosscomparative support for importance of the main obstacles we identified, we also gained support from most recent next steps in our research program (Note 3).

Another potential source of bias resides in the fact that our findings are derived from spin-off firms that survived to the time of the survey. Spin-offs that had failed to survive, fell outside our ability to observe. This is a common problem in studies on young firms. However, failure among academic spin-offs in Delft is low, witness $90 \%$ survival after six years of existence (interview with the university manager of the incubation program) and even lower than the one assessed for the EU at large (75\% after six years of existence, Mustar et al., 2007). We could collect data on the main causes of failure in Delft in the years 1995-2004 and these include friction between the team members leading to a collapse of the entrepreneurial team and severe credibility problems (personal interview with the university manager of the incubation program and with one entrepreneur that failed, as well as documentary data). These causes reflect main obstacles faced by the surviving firms in our sample. We checked for potential bias in our sample from excluding non-survivors by performing various simulation experiments including non-survived spin-offs, thereby assuming the same main obstacles for survivors and non-survivors. We increased robustness of the simulation results by assuming different levels of mortality and by comparing results in different ways (between different age-categories and within the same age-category) as follows (Appendix 2). The results indicate that assuming a mortality rate of $10 \%$ (forwarded by the program manager in Delft) does not change the significance of the difference in obstacle incidence rate between the first age category ( $<3$ years) and third age-category ( $\geq 6$ years); this is also true when assuming a higher mortality rate $(25 \%$, indicated as the overall level in EU countries, Mustar et al. 2007), be-it that the significance level is lower. We also checked whether the obstacle incidence in the third age-category ( $\geq 6$ years) in two simulated versions $(10 \%$ and $25 \%$ mortality rate) is different from the outcomes in the original sample. The tests indicate that the outcomes are not significantly different. In conclusion, there are strong indications that excluding failed spin-offs from our analysis is not a source of bias.

\section{Results: Nature of Spin-offs and Obstacles}

\subsection{Delft and Characteristics of the Spin-offs}


Delft University of Technology is in Delft, a small town (about 95.000 inhabitants) in the metropolitan area of the Randstad in the Western part of the Netherlands. Delft University of Technology started involvement in fostering growth of spin-off firms relatively late. The first official program was introduced in 1998, designed to support firms founded by graduates, students, and academic staff (BSC, 2002). This program can be qualified as rather limited (low profile), including a small loan (subordinated, interest-free), standard business courses, intermediation in finding accommodation, mentoring if needed under stressful circumstances, and some technical facilities decided upon by the faculties. The program was actually a confirmation of already ongoing practices. The program did not provide accommodation in a special incubator building; such building was under construction and almost finished at the end of the survey-period (2004). Rather, the spin-offs were to be found in faculty buildings, some vacant laboratories of the university and in a business building in the town of Delft. The program in this period can be also qualified as "low-selective" in the sense of low entry barriers (Clarysse et al. 2004) allowing a mix of spin-offs to enter the program, i.e. less ambitious ones aimed at self-employment alongside highly ambitious and highly innovative ones. Because of the low profile and low selective character of the program we have not studied the impact of support measures on the rise of obstacles. However, the limited range of the support has challenged us to investigate what additional support is needed by the most problematic spin-offs.

With regard to age of the firm, the largest category $(50.0 \%)$ was that of youngest firms ( $<3$ years), the older age groups (3-5 years and 6 years and older) were clearly smaller $(27.6$ and $22.4 \%$, respectively). Most spin-offs were relatively small, more than three-third of the spin-offs employed less than 5 persons (64.9\%) while almost 30\% employed 5 to 15 persons (28.1\%). This picture matches the general trend in the EU that university spin-off firms remain small-sized, i.e. $80 \%$ of the survivors after six years employ less than 10 persons (Mustar et al., 2007). With respect to the innovative level, more than half of the spin-offs $(53.5 \%)$ could be seen as relatively highly innovative using the definition that the product (service) qualification should be "new for the sector" or even "new as a breakthrough", and the expenditure on $R \& D$ should be a minimum of $25 \%$ of turnover (or income from other sources). Regarding activities employed, a large majority of the spin-offs was engaged in services, i.e. $70.7 \%$, of which informatics was the largest category. Next in size was engineering and various other services, like testing, optimization and simulation, mostly applied in a technology area. Approximately $40 \%$ of the service firms could be qualified as highly innovative using the above definition. A minority of the spin-offs $(29.3 \%)$ was 
engaged in manufacturing-oriented activities, like development and pilot production in bioprocess technology, lithography, sensor technology and new materials. Almost all of them could be qualified as highly innovative.

\subsection{Nature of Obstacles}

We made a distinction between different types of obstacles, like market-related, financial and management obstacles (Table 1). Market-related obstacles occur most often, with financial and management obstacles in second and third place respectively. In more detail, a lack of marketing knowledge is the most frequently experienced obstacle $(16.1 \%$ of all obstacles), followed by a shortage of sales skills (13.2\%), a lack of cash flow (12.6\%), problems in dealing with uncertainty in management $(11.5 \%)$, and management overload $10.9 \%$ ). This picture matches that in the literature with respect to most prominent problems among university spin-offs (e.g., Oakey 2003; Roberts 1991).

Table 1 Obstacles to growth (current and past)

\begin{tabular}{|l|l|c|c|l|}
\hline Categories & Specification & Abs. & $\begin{array}{l}\text { Percentage } \\
\text { share }\end{array}$ & Rank \\
\hline Market-related & Marketing knowledge & 28 & 16.1 & 1 \\
\hline & Sales skills & 23 & 13.2 & 2 \\
\hline & Customer base & 14 & 8.1 & $6 / 7$ \\
\hline Management & Dealing with uncertainty & 20 & 11.5 & 4 \\
\hline & Management (overload) & 19 & 10.9 & 5 \\
\hline Finance & Cash flow & 22 & 12.6 & 3 \\
\hline & Investment capital & 14 & 8.1 & $6 / 7$ \\
\hline & R\&D investment (development) & 7 & 4.0 & $10 / 11$ \\
\hline Physical & Accommodation & 9 & 5.2 & 9 \\
\hline & Infrastructure & 7 & 4.0 & $10 / 11$ \\
\hline & Distance (suppliers, markets, etc.) & 1 & 0.6 & 12 \\
\hline Government & Regulation, bureaucracy & 10 & 5.8 & 8 \\
\hline All obstacles & & 174 & & \multicolumn{2}{l|}{} \\
\hline
\end{tabular}

Source: Adapted from Van Geenhuizen and Soetanto, 2004.

It is not surprising that a lack of marketing knowledge is one of the main obstacles, since many spin-off firms evolve from an initial idea in a non-commercial environment to become established as a competitive profit generating firm, a stage in which new and completely different resources (knowledge) and routines are required (Vohora et al. 2004). Despite efforts by the university and incubation organization to prevent shortage in entrepreneurial capabilities, for instance, by providing courses in marketing knowledge and sales skills, these 
obstacles remain relatively prominent. Maybe it is because marketing knowledge/skills cannot be fully achieved through courses. The results of our in-depth interviews indicate that first, the markets involved are highly specialized and often niche markets whereas standard courses are not sufficiently specific to provide the knowledge needed. We mention the following examples of such markets: machinery industry for cigarette manufacturing (use of a novel coating to prevent erosion), interior design of luxury bathrooms and bathroom manufacturing (a combined shower/solarium), and logistics on sea (a ship-based self-stabilizing platform to access oil-platforms and to be used in rescue operations in general). Secondly, sales skills include skills in communication, negotiation and convincing potential customers, and these skills cannot be provided in a standard marketing course but in personal training. According to some entrepreneurs the difficulty in negotiation is to convince potential customers sufficiently about the quality of the novel product without telling them key knowledge about the non-patented invention.

An additional factor is credibility in the market. Parts of the spin-offs are subject to a vicious circle of failing to acquire a large customer, just because they had not supplied a large customer previously. Other spin-offs, however, are not bothered by achieving a customer base, because they perform research and development and pilot production together with and on specification of large companies or organizations. Our interviews provide the following examples of such customers: oil companies (novel batteries that can resist high-temperatures used in sensor systems for oil-field exploration) and aerospace organizations NASA and ESTEC (light weight composites, and light weight components and systems for use in satellites).

\section{Results: Age-patterns of Obstacles}

\subsection{Overall pattern}

We examined the occurrence of obstacles by age using two perspectives, i.e. a crosssectional one of spin-offs in different age-categories in the present situation (time of the survey) and a longitudinal one of present spin-offs looking back into their past as spin-offs (retrospective). In the discussion below attention first focuses on results from a cross-sectional perspective.

In the youngest age-class (younger than three years), different obstacles tend to arise simultaneously such as problems with cash flow, market demand, and management overload, and to a smaller extent, accommodation and infrastructure problems (Table 2). In the second and third age-class all obstacles tend to decrease in number; however this reduction occurs at 
different speed. For example, obstacles concerning accommodation are very rare in the second and third age-class, while market-related problems tend to remain. Overall, the OIR of the three age-classes $(2.79,2.38$ and 1.62, respectively) and the outcomes of the t-tests (Table 2) suggest a significant decrease in obstacles between the first and the third age-class.

Table 2. Current obstacles per age-class (cross-section)

\begin{tabular}{|l|c|c|c|}
\hline Obstacles & $\begin{array}{c}<\mathbf{3} \text { years } \\
(\mathbf{t})\end{array}$ & $\begin{array}{c}\mathbf{3 - 5} \text { years } \\
(\mathbf{t}+\mathbf{1})\end{array}$ & $\begin{array}{c}\geq \mathbf{6} \text { years } \\
(\mathbf{t}+\mathbf{2})\end{array}$ \\
\hline Market-related & 28 & 14 & 10 \\
\hline Finance & 21 & 9 & 4 \\
\hline Management & 18 & 12 & 5 \\
\hline Physical (accommodation) & 10 & 1 & 1 \\
\hline Remaining (regulation) & 4 & 2 & 1 \\
\hline All obstacles & 81 & 38 & 21 \\
\hline All spin-offs & 29 & 16 & 13 \\
\hline Obstacle incidence rate (OIR) & 2.79 & 2.38 & 1.62 \\
\hline & & & \\
\hline t-test $(\mathrm{t})$ and $(\mathrm{t}+1)$ & & 1.74 & 1.10 \\
\hline t-test $(\mathrm{t}+1)$ and $(\mathrm{t}+2)$ & & & $2.69^{*}$ \\
\hline t-test $(\mathrm{t})$ and $(\mathrm{t}+2)$ & & & \\
\hline
\end{tabular}

* Significant at the 0.05 level.

In order to identify trends in the decline of major types of obstacles faced, we measured the "obstacle reduction rate" (ORR) over the three age-classes as follows:

- $\quad 20.6 \%$ for market-related obstacles $\left(O I R_{t}\right.$ is 0.97 and $O I R_{t+2}$ is 0.77$)$

- $\quad 56.9 \%$ for financial obstacles $\left(O I R_{t}\right.$ is 0.72 and $O I R_{t+2}$ is 0.31$)$

- $\quad 61.4 \%$ for management obstacles $\left(O I R_{t}\right.$ is 0.62 and $O I R_{t+2}$ is 0.38$)$.

The reduction rates show that market-related obstacles tend to be most resistant to disappearing with age compared with other obstacles. In contrast, financial obstacles and management obstacles tend to be solved quite drastically. Note that the development pattern of financial obstacles contradicts studies on academic spin-offs in the US indicating that financial needs just increase or culminate after a few years of existence of a spin-off when (small) series production facilities are needed or when additional R\&D is necessary following the first seed-stage, as in research-intensive medical biotechnology (e.g. Van Geenhuizen, 2003; Powell et al., 2002; Roberts and Malone, 1996). 
The different situation in Delft may be attributed to the following factors: first, the presence of a large share of service firms (70.7\%) generally facing smaller investment needs, and secondly, the trend for partial self-financing; a majority of the TU Delft spin-offs (a good $70 \%$ ) undertake routine work or take part-time jobs elsewhere after some time (Van Geenhuizen and Soetanto, 2004). Strategies like these are known in the literature on small firms as bootstrapping (e.g. Ebben and Johnson, 2006). In addition, spin-off firms in short of investment capital may also refrain from investment and postpone investment to better times. The results of our in-depth interviews provide the following examples of causes of persistence of market-related problems among older spin-offs: the strategy of self-financing through routine activities in established markets thereby enabling survival without a good position in the new product's customer markets, and contracts with customers on a temporary project basis (like in software services) and failure to compose a portfolio with full coverage of the (near) future.

By taking a longitudinal view using a seven years maximum, i.e. year zero to year six, it becomes clear that obstacles experienced during first years tend to decline substantially at age two to three, but this decline tends to fall back at age four (Table 3). Overall, the reduction rate is $62.1 \%$ meaning that in seven years there is a strong decrease in obstacles to growth. The fall in reduction rate at age four reflects failure in gaining stable relations with customers and liability in becoming independent in gaining key resources. The downturn of the macroeconomy in the Netherlands in the years 2001 to 2003 can be excluded as a major external factor because the firms in this age-category were already four years old in the years prior to the downturn.

Table 3. Obstacles per age (longitudinal) (a)

\begin{tabular}{|c|c|c|}
\hline Age (N) & Obstacles incidence (OIR) & Obstacle reduction rate (ORR) \\
\hline $0(58)$ & 2.34 & -0.43 \\
\hline $1(55)$ & 2.33 & -18.45 \\
\hline $2(50)$ & 1.90 & -30.00 \\
\hline $3(45)$ & 1.33 & -6.77 \\
\hline $4(29)$ & 1.24 & -16.13 \\
\hline $5(24)$ & 1.04 & -14.42 \\
\hline $6(18)$ & 0.89 & -61.96 \\
\hline \multicolumn{2}{|l|}{ Obstacle reduction rate age 0 to age 6 } \\
\hline
\end{tabular}

$\mathrm{N}=$ nr of spin-offs.

a. Note that the decreasing number of firms by age (from 58 to 18 ) mainly reflects the relatively young agestructure of the sample (a relatively high founding activity in 2000-2003). 
If we take a closer look at spin-offs at age four or shortly before, it becomes clear that a majority of them $(70.0 \%)$ tend to face market-related and/or financial obstacles (Table 4). Within this category, most spin-offs also tend to encounter management problems relatively frequently (71.4\%). Accordingly, failure in the market and financial shortage urge the spinoffs to try various new models and strategies shortly after each other (or simultaneously) leading to management overload and problems of uncertainty. Failure in gaining stable relations with customers and/or investors at age four complies with credibility as a major juncture preventing spin-offs to progress and move into next stage (Vohora et al. 2004). This development is exemplified by a spin-off whose product is a robotic tool for agro-industries (automated irrigation system). Obstacles in finding capital and in connecting with customers became serious at age three, reason why the spin-off started to provide technical consultation in another market (analysis of anchoring systems for wind turbines) and to develop several related products (e.g. a pneumatic gear shifting system). However, this broadening has caused management problems at age four and made gaining credibility based on the novel product even more difficult. In addition, accumulation of problems at age four may in general be reinforced by the wish or need of spin-offs in the incubation program to become independent from this program and by some pressure felt to pay back the initial loan.

Table 4 Market and/or financial obstacles and management obstacles

\begin{tabular}{|l|c|c|c|}
\hline & $\begin{array}{c}\text { Management obstacles } \\
\text { at age 4 }\end{array}$ & $\begin{array}{c}\text { No management } \\
\text { obstacles at age 4 }\end{array}$ & Totals a) \\
\hline $\begin{array}{l}\text { Market and/or } \\
\text { financial obstacles at } \\
\text { age 4 or shortly before }\end{array}$ & $20(71.4 \%)$ & $8(28.6 \%)$ & $28(100 \%)$ \\
\hline $\begin{array}{l}\text { No such obstacles at } \\
\text { age 4 or shortly before }\end{array}$ & $1(8.3 \%)$ & $11(91.7 \%)$ & $12(100.0 \%)$ \\
\hline Totals & $21(52.5 \%)$ & $19(47.5 \%)$ & $40(100.0 \%)$ \\
\hline
\end{tabular}

a) Number of spin-offs of at least $3 / 4$ years old: 40

$\mathrm{Chi}^{2}=13.41^{* * *}$ (significant at the 0.00 level).

\subsection{Do Highly Innovative Spin-offs Develop Differently?}

Highly innovative spin-offs $(53.5 \%)$ were defined in this study on the basis of their product (service) qualification as "new for the sector" or even "new as a breakthrough", and on the basis of spending a minimum of $25 \%$ of turnover (or other income) on R\&D. The cross-sectional results in Table 5 suggest that highly innovative spin-offs face a relatively 
high obstacle incidence rate in the first years, i.e. 3.21 versus 1.90 among low- to medium innovative spin-offs, a difference that is statistically significant. In the next two age-classes, highly innovative spin-offs tend to overcome (or prevent) obstacles quite successfully, whereas medium to low-innovative spin-offs first face an increased obstacle incidence rate. Overall, highly innovative spin-offs tend to face more initial problems than medium to low innovative spin-offs but show a stronger decrease in later years, witness an OIR of 1.20 (versus 1.88) in the third age-class. The latter results are supported by outcomes of a t-test: the difference in obstacle incidence rate between the first and third age-class is significant only for highly innovative spin-offs.

Table 5. Current obstacles (OIR) per age-class (cross-section)

\begin{tabular}{|c|c|c|c|}
\hline Age Category & $\begin{array}{c}\text { Highly innovative } \\
\text { spin-offs (HIS) }\end{array}$ & $\begin{array}{c}\text { Med-Low innovative } \\
\text { spin-offs (MLIS) }\end{array}$ & $\begin{array}{c}\text { t-test } \\
\text { HIS and MLIS }\end{array}$ \\
\hline$<3$ years $(\mathrm{t})$ & 3.21 & 1.90 & $2.239^{*}$ \\
\hline 3-5 years $(\mathrm{t}+1)$ & 2.71 & 2.11 & 0.102 \\
\hline$\geq 6$ years $(\mathrm{t}+2)$ & 1.20 & 1.88 & 1.365 \\
\hline Total OIR & 2.77 & 1.96 & \\
All spin-offs & 31 & 27 & \\
All obstacles & 86 & 53 & \\
& & & \\
$\mathrm{t}$-test $(\mathrm{t})$ and $(\mathrm{t}+1)$ & $2.207^{*}$ & 0.040 & \\
$\mathrm{t}$-test $(\mathrm{t}+1)$ and $(\mathrm{t}+2)$ & 1.761 & 0.398 & \\
$\mathrm{t}$-test $(\mathrm{t})$ and $(\mathrm{t}+2)$ & $3.077^{* *}$ & 0.459 & \\
\hline
\end{tabular}

* significant at the 0.05 level; ** significant at the 0.01 level.

The analysis of longitudinal data allowed us only to picture broad, tentative patterns, because of the small size of the sub-samples (Table 6). The number of obstacles among highly innovative firms tends to increase right after start as witnessed by obstacle incidence rates of 2.32 and 2.51, but this is followed by a decrease at higher rates rather than among medium to low innovative spin-offs. Among the last category, age four shows a stagnation of obstacle reduction, with a remaining $62 \%$ of obstacles at age six. This indicates a continued struggle against credibility obstacles preventing low to medium-innovative spin-offs to enter next growth stage and deal with issues of sustainable returns. However, at age six, highly innovative spin-offs tend to be free from all obstacles.

The relatively problematic age of zero to one of most high-technology spin-offs refers to credibility problems in the sense that major resources still need to be acquired and stable market relations need to be established. These hurdles to growth tend to be stronger than the ones among low to medium innovative spin-offs experienced at the same age. However, if 
highly innovative spin-offs have taken these hurdles, they tend to move more smoothly to sustainable growth. Apparently, highly innovative spin-offs attempt to overcome initial obstacles more quickly and more professionally because of greater potential return in a market monopoly. This is exemplified by a spin-off dealing with the design of a novel analog circuit which is highly capital-intensive. The market was a small niche in the automotive industry dominated by a few global players as potential customers. Attempts to convince one of them of the quality of the product failed, reason why quite soon the spin-off turned to its former university professor(s) for formal intermediation and recommendation. This strategy was effective in gaining a substantial contract at the age of one. Another example of professional approach is to contract a good-reputation sales agent.

Table 6. Obstacles by age (longitudinal)

\begin{tabular}{|c|c|c|c|c|}
\hline \multirow{2}{*}{$\begin{array}{c}\text { Age (nr of HIS, } \\
\text { MLIS) }\end{array}$} & \multicolumn{2}{|c|}{$\begin{array}{c}\text { Highly innovative spin-offs } \\
\text { (HIS) }\end{array}$} & \multicolumn{2}{c|}{$\begin{array}{c}\text { Medium-Low innovative spin-offs } \\
\text { (MLIS) }\end{array}$} \\
\cline { 2 - 5 } & $\begin{array}{c}\text { Obstacles } \\
\text { incidence } \\
\text { (OIR) }\end{array}$ & $\begin{array}{c}\text { Reduction } \\
\text { rate } \\
\text { (ORR) }\end{array}$ & $\begin{array}{c}\text { Obstacles } \\
\text { incidence } \\
\text { (OIR) }\end{array}$ & $\begin{array}{c}\text { Reduction rate } \\
\text { (ORR) }\end{array}$ \\
\hline $0(31,27)$ & 2.32 & & 2.20 & \\
\hline $1(29,26)$ & 2.51 & 8.19 & 2.15 & -2.27 \\
\hline $2(24,26)$ & 1.83 & -27.09 & 1.88 & -12.56 \\
\hline $3(21,24)$ & 0.90 & -50.82 & 1.67 & -11.17 \\
\hline $4(12,17)$ & 0.58 & -35.55 & 1.59 & -4.79 \\
\hline $5(10,14)$ & 0.20 & -65.52 & 1.50 & -5.66 \\
\hline $6(7,11)$ & 0.00 & -100.00 & 1.36 & -9.33 \\
\hline $\begin{array}{c}\text { Obstacle reduction } \\
\text { rate age 0 to 6 }\end{array}$ & & -100.00 & & -38.18 \\
\hline
\end{tabular}

The results of the above longitudinal analysis broadly comply with those of the crosssectional analysis, be-it that the results of the cross-sectional analysis suggest a higher problem incidence among highly innovative spin-offs that are young than the longitudinal analysis. We may forward the following explanation for this difference: young and highly innovative spin-offs at the time of the survey (in 2003/4) tend to be more strongly affected by credibility problems connected with the downturn of the economy than older spin-offs that were young in years facing more favorable economic conditions. In addition, the crosssectional results indicate that highly innovative spin-offs in their first years are more vulnerable to impacts from an economic downturn than medium to low innovative spin-offs. 
An early occurrence of credibility problems among highly innovative spin-offs tends to be related with high ambitions to become quickly independent from the incubator and do it all in a professional way, including strategic thinking, conscious learning, delegation and contracting external professionals. Our results do not point to the occurrence of a threshold of sustainable returns at a particular age within the period of six year. Many highly innovative spin-offs seem to organize their venture at the start and in the first year in a professional manner, including overcoming the obstacle of lack of entrepreneurial commitment. The last obstacle tends to happen more often among highly innovative spin-offs established by university staff due to various risks perceived, like to lose his/her faculty position and to lose access to key university facilities. Our in-depth interviews indicate that these risks may be reduced at the start by negotiation with the faculty board e.g. leading to a guaranteed return to the academic position within a limited number of years and permission to use particular laboratory equipment. Under such conditions, the threshold of credibility can be taken soon and the threshold of sustainable returns can be taken within the next five/six years. This development is exemplified by a spin-off founded by a university technician who designed equipment to produce novel solar cells using a specific thin-film technology. Full-time work to improve the equipment (enabled by protection against risk of failure for two years) and access to facilities of the university laboratory contributed to a quick development of the spinoff. All in all, it took seven years to prove the feasibility of the technology and to exercise its up-scaling to full production lines, given a growing interest of investors and a growing market demand.

Next, we examined whether highly innovative spin-offs in manufacturing are more vulnerable to credibility obstacles than highly innovative spin-offs in services. It appears that the majority of spin-offs engaged in manufacturing activity are facing market- and/or financial obstacles in year zero to one $(87.5 \%)$, whereas this is just less than $50 \%$ among spinoffs firms engaged in services (Table 7). Many of the first category's products, like in sensor technology, control systems, and new materials and material technology, lack a market in the first years, except for products developed in co-makership or commissioned by a large customer. The difference in occurrence of problematic first years is significant and suggests that a high-technology profile in manufacturing tends to be more vulnerable to credibility problems than in services, a situation that seems primarily connected to higher levels of financial investment (e.g. for prototype development and pilot production) and less flexibility in switching to other, potentially more promising product-markets. 
Table 7 Highly innovative spin-offs (HIS) according to type of activity and obstacles

\begin{tabular}{|l|c|c|c|}
\hline & $\begin{array}{l}\text { Market and/or financial } \\
\text { obstacles at age 0-1 }\end{array}$ & $\begin{array}{c}\text { No such } \\
\text { obstacles }\end{array}$ & Totals a) \\
\hline Manufacturing & $14(87.5 \%)$ & $2(12.5 \%)$ & $16(100 \%)$ \\
\hline Services & $7(46.7 \%)$ & $8(53.3 \%)$ & $15(100 \%)$ \\
\hline Total number of spin-offs & $21(67.7 \%)$ & $10(29.0 \%)$ & $31(100 \%)$ \\
\hline
\end{tabular}

a) Number of highly innovative spin-offs: 31 .

$\mathrm{Chi}^{2}: 5.91$ (significant at the 0.01 level).

The above contrast can be illustrated with two rather extreme spin-offs. The first one designed and constructed the components of luxurious bath cabins combining shower and solarium, but started to face problems in financing the building of a prototype (approximately 80,000 euro shortage) and in finding customers (found only in year five). By contrast, at a low level of capital investment the second spin-off developed a new email system based on open source technology that could be sold with some adjustments within six months after establishment. Moreover, this spin-off easily received credibility from customers worldwide by switching to develop somewhat different systems later on. We now turn to specific needs for support that follow from the accumulation of obstacles in year zero to one among highly innovative spin-offs, particularly those in manufacturing sectors.

The range of incubation support at the time in Delft was rather limited but the new incubation program - launched in 2005 - intended to attract mainly highly innovative spinoffs and to extent support accordingly. Therefore we paid specific attention in the questionnaire to suggestions for additional support. It appeared that a majority of highly innovative spin-offs facing problematic first years have a demand for extension of current support, particularly for networking with the university (63\%) (Note 4). This need for networking is concerned with access to new technology and use of facilities like computing and software licenses, as well as collaboration with research professors. In addition, according to the spin-offs universities preferably act as launching customers and agents in international marketing, and connect with potential partner firms and investment to increase credibility.

\subsection{The age of particular thresholds}

On the basis of the above analysis we may summarize the results on ages at which particular thresholds tend to arrive (Table 8). Among medium- to low innovative spin-offs the age at which the credibility threshold - concerned with stable relations with customers and liability in gaining resources independently - manifests relatively strongly tends to be four years. This is followed by relatively low levels of obstacle reduction indicating that many 
spin-offs are still dealing with credibility issues at later ages preventing to reach the stage of sustainable returns within six years (a reduction rate of 38\% at age six). The entrepreneurial commitment threshold seems to happen only incidentally in this category of spin-offs because the commitment needed is relatively small due to less risk-taking. By contrast, highly innovative spin-offs tend to encounter both the entrepreneurial commitment threshold and the credibility threshold in years zero to one. In this sense, their first years are problematic. These years are however followed by five/six years of substantial problem reduction (a reduction rate of $100 \%$ at age six). Note that highly innovative spin-offs tend to face less difficulty in passing thresholds by acting more professionally than other spin-offs in finding solutions, reason why they can pass more quickly.

Next threshold, sustainable results, cannot be observed as an accumulation of problems in a particular age-category. Most low- to medium-innovative spin-offs fail to reach this threshold before the age of six, due to persistence of credibility problems (market). By contrast, highly innovative spin-offs tend to take this threshold spread in time before the age of six, as they appear to be free from any obstacles at that age. However, this threshold may also arise after the age of six, but this was beyond our observation.

Table 8 Tentative ages (0-6 years) of thresholds and difficulty in passing them

\begin{tabular}{|l|l|l|l|l|l|}
\hline & \multicolumn{2}{|l|}{$\begin{array}{l}\text { Medium- to low innovative } \\
\text { spin-offs }\end{array}$} & \multicolumn{2}{l|}{ Highly innovative spin-offs } \\
\hline $\begin{array}{l}\text { Type of } \\
\text { threshold }\end{array}$ & $\begin{array}{l}\text { Tentative } \\
\text { ages }\end{array}$ & $\begin{array}{l}\text { Difficulty in } \\
\text { passing }\end{array}$ & Tentative ages & $\begin{array}{l}\text { Difficulty in } \\
\text { passing }\end{array}$ \\
\hline $\begin{array}{l}\text { Entrepreneurial } \\
\text { commitment }\end{array}$ & $\begin{array}{l}\text { Tends to } \\
\text { occur less } \\
\text { often }\end{array}$ & $\begin{array}{l}\text { More difficult to } \\
\text { pass }\end{array}$ & Year 0 - 1 & $\begin{array}{l}\text { Less difficult: a quick } \\
\text { passing due to } \\
\text { professional solutions }\end{array}$ \\
\hline Credibility & Year 4 & $\begin{array}{l}\text { More difficult; } \\
\text { passing takes a } \\
\text { long time }\end{array}$ & Year 0 - 1 & $\begin{array}{l}\text { Less difficult: a quick } \\
\text { passing due to } \\
\text { professional solutions }\end{array}$ \\
\hline $\begin{array}{l}\text { Sustainable } \\
\text { results }\end{array}$ & $\begin{array}{l}\text { Often not } \\
\text { reached } \\
\text { before } \\
\text { Year 6 }\end{array}$ & $\begin{array}{l}\text { Not known } \\
\text { (beyond the } \\
\text { study) }\end{array}$ & $\begin{array}{l}\text { Tends to be } \\
\text { spread in time; } \\
\text { may also arise } \\
\text { after Year 6 }\end{array}$ & $\begin{array}{l}\text { Probably less difficult, } \\
\text { due to a professional } \\
\text { approach in passing }\end{array}$ \\
\hline
\end{tabular}




\section{Concluding Remarks and Policy Implications}

In this article we have sought to identify at which ages academic spin-off firms face an accumulation of obstacles and how the incidence of obstacles decreases, using ideas about different needs for resources in a stage-based approach. We particularly focused on hightechnology spin-offs and on identifying the ages of critical thresholds to growth. We believe that our study of Delft University of Technology has a meaning beyond the local, i.e. for technical universities employing a low profile program located in a similar national innovation system and according perceptions on entrepreneurship and entrepreneurial failure, like in Norway and Sweden, and partly Austria and Switzerland (GEM Monitor 2007).

Our findings make a twofold contribution to knowledge. We clarified and developed particular problematic stages in development models on academic spin-off firms and particular segments of them by exploring trends in obstacles to growth using both cross-sectional and longitudinal data. We found in an overall pattern that market-related problems tend to be most resistant over time (a reduction rate of $21 \%$ in the age-category of six years and older). Remarkably, financial problems tend to be solved more quickly (a reduction rate of $57 \%$ in this age-category), a situation typical for service firms and for firms preferring self-financing. We were able to add to theory on stage-based development of academic spin-offs, by identifying in a preliminary way the age-dimension of the credibility threshold and the threshold of sustainable returns (Vohora et al. 2004). Mainly due to low to mediuminnovative spin-offs, the age at which the credibility threshold is seriously manifesting tends to be four years. This is followed by relatively low levels of obstacle reduction. By contrast, highly innovative spin-offs tend to encounter the credibility threshold (and in some cases still the entrepreneurial commitment threshold) as early as years zero to one, followed by four years of substantial problem reduction (a reduction rate of $100 \%$ at age six). Next threshold, sustainable results, could not be observed as an accumulation of problems in a particular agecategory. Most low- to medium-innovative spin-offs fail to reach this threshold before the age of six, whereas highly innovative spin-offs tend to take this threshold spread in time before the age of six (free from any obstacles at that age). In addition, our results produce evidence for first-mover advantages in the sense that highly innovative spin-offs tend to be successful in avoiding obstacles right after a problematic start due to a professional attitude and adoption of various important abilities, like strategic planning and delegation of tasks, most probably enhanced by a greater potential return in a market monopoly. However, a downturn of the economy may weaken the results of this behavior. Overall, the age-patterns of obstacles 
suggest that highly innovative spin-offs overcome the critical thresholds of credibility and sustainable returns more quickly compared with low to medium-innovative spin-offs. The above results would call for various extensions of the model of Vohora et al. (2004) in terms of ages at which the credibility threshold occurs, particularly different age-lines for highly innovative spin-offs compared with other spin-offs connected with first-mover advantages, as well as including influence of macro-economic development on highly innovative spin-offs.

As a second contribution, our results have increased knowledge that can be used in practice of fostering academic spin-off firms. A major result is the need to adopt a differentiated approach in designing support programs for academic spin-offs, given diversity in age, sector and innovation intensity. Using the outcomes of the study we may provide some practical guidelines. Before a support program is designed (redesigned) the characteristics of the target spin-offs need to be clarified. Programs aimed at nurturing highly innovative spinoffs in manufacturing should include early and more substantial support, particularly supply of networking with/through the university and of activity of the university as launching customer and intermediary agent in export relations. This may be particularly important in a period of economic downturn. The rise of credibility problems at the age of four years among medium to low innovative spin-offs suggests that support should not be stopped at that age (as is often the case) but continued and focus on particular needs in preventing/solving credibility problems through early personal training of entrepreneurs to develop skills in connecting (negotiating) with potential market partners and in building a good mix of such partners. The last recommendation complies with recent ideas that networking, as the main ingredient to enhance performance, should be based on the right strategy, i.e. including sufficient openness and variation of partners (Van Burg et al., 2008; Hughes et al., 2007; Walter et al., 2006). Early support and training in profitable networking may prevent a situation in which large numbers of spin-offs survive at older ages without stable customer relations and as a result, without the power to grow.

Overall, the mortality rate among academic spin-offs in Delft is rather low. This situation raises the following question. Are large parts of the small and slowly growing firms just surviving due to receiving support, even if this is low profile? If this is true, it might be questioned whether access criteria to support programs should be more rigid and structured in such a way that mainly those spin-offs are selected that reach the stage of sustainable growth in a period of approximately six years or earlier? We recommend a conscious screening, in any case including criteria to prevent spin-offs without sufficient entrepreneurial commitment to enter the program. A conscious screening is however not easy, because it should also match 
with the general goal of the program, e.g. low failure rates, abundant job creation, top level innovation, or high-value exit options. Although entry policies of university incubators and assessment methodologies for new technology ventures are not new (see, e.g. De Coster and Butler, 2005; Mian 1994), understanding which method produce the spin-off growth that is wanted is limited (Aerts et al. 2007). The aim to produce more quickly growing spin-offs together with other characteristics calls for more research on effective screening criteria.

The study is the first of its kind by measuring of obstacles to growth at different ages drawing on a medium-sized sample. Despite the rather consistent results on spin-offs' development, the study is facing two constraints. First, recent changes in the institutional context in Delft "undermine" the findings of this study. A more sophisticated incubation program jointly undertaken by the university and the municipality of Delft in 2005, including e.g. supply of units in an incubator building and entrepreneurial courses ranging from opportunity recognition to negotiation with potential customers renders the previous experiences somewhat useless in the context of Delft. However, as previously indicated the study up to 2005 produces various new insights that carry relevance beyond the context of Delft. Secondly, the sample size was rather small, including small subcategories of spin-offs, and this has prevented attempts to rigorous modeling and testing. Accordingly, future research should include spin-offs from a number of other universities, and this plan complies with the recently addressed need to study the development of spin-off firms using larger databases, including longitudinal data (Zhang, 2009). 


\section{Acknowledgement}

This study is part of the Delft Center of "Sustainable Urban Areas", of Delft University of Technology, Delft, The Netherlands.

\section{Note 1}

The limitation of the study to spin-offs in Delft has not caused a bias in the results because relocation occurred for a rather small number of spin-offs (four). For two spin-offs, relocation was connected with fast growth and with the need for accommodation qualified as an obstacle. Other reasons for relocation from Delft occurred as a result of expiring of a temporary rent contract and lack of a quick alternative in Delft, and availability of better facilities and proximity to customers in another region in the Netherlands (personal interview with manager of the incubation program and documentary data).

\section{Note 2}

Traditionally, the term longitudinal is limited to studies with repeated real-time observations (e.g. LeonardBarton, 1990) but we use the term in a broader sense, including retrospective analysis.

\section{Note 3}

The three main obstacles turned out to be good predictors of growth of the spin-off firms concerned, aside from various network indicators. All models we tested to explain growth (various partial models, full model, growth in different urban/regional circumstances, and growth of very young and somewhat older spin-off firms) indicate that obstacles related with market, management and financial shortages hamper growth. The effect is consistently on a high level of statistical significance, i.e. 95\% and 99\% (Soetanto and Van Geenhuizen, 2009a, 2009b).

\section{Note 4}

Cross-tabulation of type of spin-off (HIS in problematic first year(s) versus other spin-offs) with support suggestions (networking with/through the university) indicates a significant difference between the two types of spin-offs. Chi ${ }^{2}: 3.93$ (significant at the 0.05 level). 


\section{Appendix 1}

The obstacle incidence rate (OIR) is calculated by dividing the total number of obstacle per agecategory (class or year) by the number of spin-offs in that category, as follows:

Obstacle incidence rate $(\mathrm{OIR})=\frac{\sum_{i=0}^{t} o_{i}}{\sum_{i=0}^{n} x_{i}}$

$O=$ number of obstacles per age (class)

$X=$ number of spin-offs in the age (class)

$t \quad=$ age category or year

$n \quad=0,1,2, \ldots$

Accordingly, an OIR of 1.00 for a particular age (class) means that one spin-off firm faces on average one obstacle to growth. ORR depicts the increase/decrease of numbers of obstacles between different ages. The obstacle reduction rate $(O R R)$ is measured by dividing the difference of OIR between two age-classes with the initial $O I R$, as follows:

Obstacle reduction rate $(O R R)=\frac{O I_{t+n}-O I_{t}}{O I_{t}} \times 100 \%$

$O I R_{t}=$ obstacle incidence rate in the $t$ age (class)

$O I R_{t+n}=$ obstacle incidence rate in the $t+n$ age (class)

$t \quad=$ age (class)

$n \quad=0,1,2, \ldots$

\section{Appendix 2 Simulation experiments}

2.1

The table shows a comparison of obstacle incidence between the first age-category ( $<3$ years) and two versions of the third age category ( $\geq 6$ years) assuming a mortality rate of $10 \%$ and $25 \%$ respectively.

\begin{tabular}{|l|c|c|}
\hline Obstacles included in simulation & $<$ 3 years $(\mathbf{t})$ & $\mathbf{z}$ years $(\mathbf{t}+\mathbf{2})$ \\
\hline Simulation 1 (a) & 28 & 12 \\
Market-related & 21 & 6 \\
Financial & 18 & 5 \\
Management & 81 & 25 \\
Total number of obstacles & 29 & 15 \\
Total number of spin-offs & 2.79 & 1.67 \\
Obstacle incidence rate (OIR) & & $2.40^{*}$ \\
\hline$t$-test: $(t)-(t+2)$ & 28 & 14 \\
\hline Simulation 2 (b) & 21 & 8 \\
Market-related & 18 & 5 \\
Financial & 81 & 29 \\
Management & 29 & 17 \\
Total number of obstacles & 2.79 & 1.71 \\
Total number of spin-offs & & $2.14+$ \\
Obstacle incidence rate $($ OIR) & & \\
\hline -test $(t)-(t+2)$ & & \\
\hline
\end{tabular}

* Significant at the 0.05 level; + significant at the 0.10 level. Notes:

(a) Assumption of a mortality rate of $10 \%$ for the age-category 6 years and older (two additional spin-offs).

(b) Assumption of a mortality rate of $25 \%$ for the age-category 6 years and older (four additional spin-offs). 
2.2

The table shows a comparison of obstacle incidence between three versions of the third age category ( $\geq 6$ years): the original sample, the version under the assumption of $10 \%$ mortality rate (S1) and the version under the assumption of $25 \%$ mortality rate (S2).

\begin{tabular}{|l|c|c|c|}
\hline & $\begin{array}{c}\text { Original Sample } \\
(\text { OS) }\end{array}$ & $\begin{array}{c}\text { Simulation 1 } \\
\text { (S1) }\end{array}$ & $\begin{array}{c}\text { Simulation 2 } \\
\text { (S2) }\end{array}$ \\
\hline Obstacles & $\begin{array}{c}\mathbf{6} \text { years } \\
(\mathbf{t}+\mathbf{2})\end{array}$ & $\begin{array}{c}\geq \mathbf{6} \text { years } \\
(\mathbf{t}+\mathbf{2})\end{array}$ & $\begin{array}{c}\geq \mathbf{6} \text { years } \\
(\mathbf{t}+\mathbf{2})\end{array}$ \\
\hline Market-related obstacles & 10 & 12 & 14 \\
\hline Financial obstacles & 4 & 6 & 8 \\
\hline Management obstacles & 5 & 5 & 5 \\
\hline Total number of obstacles & 21 & 25 & 29 \\
\hline Total number of spin-offs firms & 13 & 15 & 17 \\
\hline Obstacle incidence rate $($ OIR) & 1.62 & 1.67 & 1.71 \\
\hline Levene test & & OS-S1: $0.124^{*}$ & OS-S2: $0.885^{*}$ \\
\hline t-test & & OS-S1: $0.306^{*}$ & OS-S2: $0.543^{*}$ \\
\hline
\end{tabular}

* Not significant. 


\section{References}

Aerts, K., P. Matthyssens, K. Vandenbempt, 2007. Critical role and screening practices of European business incubators, Technovation 27, 254-267.

Barney, J., 1991. Firm Resources and Sustained Competitive Advantage, Journal of Management, 17 (1) 99-120.

Barney, J. B., 2006. Gaining and Sustaining Competitive Advantage (3 ${ }^{\text {rd }}$ ed.), Englewood Cliffs (NJ): Prentice Hall.

Blaydon, C., Keogh, W. Evans, G., 1999. Managerial skills development in R\&D based NTBFs assisting managers to manage. International Journal of Entrepreneurial Behaviour and Research, 5 (4) 173-185.

Bøllingtoft, A., Ulhøi, J.P., 2005. The networked business incubator - leveraging entrepreneurial agency?, Journal of Business Venturing, 20, 265-290.

Bradburn, N. M., Rips, L.J., Shevell, S. K., 1987. Answering Autobiographical Questions: the Impact of Memory and Inference on Surveys, Science 236 (4798).

BSC (Business Service Center, TU Delft), 2002, Established in Delft, $2^{\text {nd }}$ edition. Delft, Business Service Center TU Delft.

Burg, E. van, Romme, A., Georges, L., Gilsing, V.A., Reyman, I.M.M., 2008. Creating University Spin-Offs: A Science-Based Design Perspective, Journal of Product Innovation Management 25 (2), pp. 114-128.

Charles, D., 2003. "Universities and territorial development: reshaping the regional role of English universities", Local Economy, 18 (1), 7-20.

Clarysse, B., Wright, M., Lockett, A., Velde, E. van de, Vohora, A., 2004. Spinning out new ventures: a typology of incubation strategies from European research institutions, Journal of Business Venturing, 20 (2), 183-216.

Cooper, S., Hetherington, L., 2005. Developing Entrepreneurial Capability to Facilitate Academic Entrepreneurship and Technology Commercialisation, in: During , W., R. Oakey and S. Kauser (eds) New Technology-Based Firms in the New Millennium, Volume IV, Elsevier, Amsterdam, 23-40.

De Coster, R., Butler, C., 2005. Assessment of proposals for new technology ventures in the UK: characteristics of university spin-off companies, Technovation 25, 535-543.

Denzin, N.K., 1978. Sociological methods: A source book, McGraw-Hill, New York.

Druilhe, C., Garnsey, E., 2004. Do Academic Spin-Outs Differ and Does it Matter? Journal of Technology Transfer, 29, 269-285.

Ebben, J., Johnson, A., 2006. Bootstrapping in small firms: An empirical analysis of change over time, Journal of Business Venturing, 21, 851-865.

European Commission, 1995. European Commission, Green Paper on Innovation, EC, Brussels.

Fowler, F.J., 2002. Survey Research Methods, Sage Publishers, Thousands Oaks.

Geenhuizen, M. van, 2003. How can we reap the fruits of academic research in biotechnology? In search of critical success factors in policies for new firm formation. Environment and Planning C, 21, 139-155.

Geenhuizen, M. van, Gibson, D., Heitor, M. V. (eds) 2005. Regional Development and Conditions for Innovation in the Network Society, West Lafayette: Purdue University Press.

Geenhuizen, M. van, Soetanto D.P., 2004. Academic Knowledge and Fostering Entrepreneurship: An Evolutionary Perspective. In: Groot, H., Nijkamp, P., and Stough, R., (eds) Evolutionary Approaches to Innovation. London: Edward Elgar, 252-268.

GEM, Global Entrepreneurship Monitor 2007, Executive Report, London Business School and Babson College.

Greiner, L., 1972. Evolution and revolution as the organisation grows, Harvard Business Review, 50: 37-46.

Hackett, S. M, Dilts, D. M., 2004. A Real Option-Driven Theory of Business Incubation, Journal of Technology Transfer, 29, 41-54.

Heirman, A., Clarysse, B., 2004. How and Why do Research-Based Start-Ups Differ at Founding? A ResourceBased Configurational Perspective, Journal of Technology Transfer, 29, 247-268.

Hoang, H., Antoncic, B., 2003. Network-based research in entrepreneurship: a critical review. Journal of Business Venturing, 17, 1-23.

Hughes, M., Duane Ireland, R, Morgan, R.E., 2007. Stimulating Dynamic Value: Social Capital and Business Incubation as a Pathway to Competitive Success, Long Range Planning, 40, 154-177.

Kerin, R.A., Varadarajan, P.R., Peterson, R.P., 1992. First-Mover Advantage: A Synthesis, Conceptual Framework, and Research Propositions, Journal of Marketing, 56 (October), 33-52.

Kroll, H., Liefner, I., 2008, Spin-off enterprises as a means of technology commercialization in a transforming economy-Evidence from three universities in China, Technovation, 28, 298-313.

Leonard-Barton, D., 1990. A Dual Methodology for Case Studies: Synergistic Use of a Longitudinal Single Site with Replicated Multiple Sites, Organization Science 1 (3), 248-266

Lieberman. M.B., Montgomery, D.B., 1998. First-mover (dis)advantages: retrospective and link with the resource-based view", Strategic Management Journal, 19, 1111-1125. 
Locket, A., Siegel, D.S., Wright, M. Ensley, M., 2005. The creation of spin-off firms at public research institutions: managerial and policy implications, Research Policy, 34, 981-993.

Kazanjian, R.K. and Drain, R. 1989, An empirical test of a stage of growth progression model, Management Science 35 (12) 1489-1504.

Mangematin, V., S. Lemarié, J.P. Boissin, D. Catherine, F. Corolleur, R. Coronini, Trommetter, M, 2003. "Development of SMEs and heterogeneity of trajectories: the case of biotechnology in France". Research Policy, 32, 621-638.

McAdam, M., McAdam, R., 2008. High-tech start-ups in University Science Park incubators: The relationship between the start-up's lifecycle progression and use of the incubator's resources, Technovation 28 (5) 277-290.

Mian, S., 1997. "Assessing and managing the university technology business incubation: an integrative framework", Journal of Business Venturing, 12 (3), 251-285.

Mustar, P., Renault, M., Colombo, M., Piva, E., Fontes, M., Locket, A., Wright, M., Clarysse, B., Moray, N., 2006. Conceptualising the heterogeneity of research-based spin-offs: a multidimensional taxonomy, Research Policy, 35 (2), 289-308.

Mustar, P., Clarysse, B, Wright, M., 2007. University spin-off firms in Europe: What have we learnt from ten years experience? Position paper, Prime General Conference, 2007.

Niosi, J., 2006. Success Factors in Canadian Academic Spin-offs, Journal of Technology Transfer 31: 451-457.

Oakey, R.P., 2003. Technical entrepreneurship in high technology small firms: some observations on the implications for management, Technovation, 23, 679-688.

O’Shea, R.P. Chugh, H., Allen, T.J., 2008. Determinants and consequences of university spinoff activity: a conceptual framework, Journal of Technology Transfer, 33, 653-666.

Perez, M.P., Sanchez, A.M., 2003. The development of university spin-offs. Early dynamics of technology transfer and networking. Technovation, 23 (10), 823-831.

Pirnay, F., Surlemont, B., Nlemvo, F., 2003. Toward a typology of university spin-offs, Small Business Economics, 21 (4), 355-369.

Rasmussen, E., 2008. Government instruments to support the commercialization of university research: lessons from Canada, Technovation, 28 (8): 506-517.

Reid, S., Garnsey, E., 1998. "Incubation Policy and Resource Provision: Meeting the Needs of Young, Innovative Firms". In: Oakey, R. and W. During (eds) New Technology Based Firms in the 1990s, Volume V. London: Paul Chapman, 67-80.

Roberts, E. B., 1991. Entrepreneurs in High Technology. Lessons from MIT and Beyond. New York: Oxford.

Rothaermel, F., Thursby, M., 2005. University-incubator firm knowledge flows: assessing their impact on incubator firm performance. Research Policy 34 (3), 305-324.

Shane, S., 2004. Academic entrepreneurship: University spin-offs and wealth creation. Northampton (MA), Edward Elgar.

Soetanto, D.P., Geenhuizen, M. van, 2007. University Spin-offs at Different Ages: In Search of Obstacles to Better Match Support. In: Groen, A., Oakey, R., Sijde, P. van der, and Kauser, S. (eds) New Technology Based Firms in the New Millennium, Volume VI. Amsterdam: Elsevier, 23-37.

Soetanto, D.P., Geenhuizen, M. van, 2009a. Social networks and competitive growth of university spin-off firms. Journal of Economic and Social Geography 100 (2), 198-209.

Soetanto, D.P., Geenhuizen, M. van, 2009b. Social Capital in Early Years: Networks on the Way to Competitive Growth of University Spin-off Firms, The $7^{\text {th }}$ Interdisciplinary Conference on Entrepreneurship Research (IECER), Lisbon, March 4-6 2009.

Vakratsas, D., Rao, R.C., Kalyanaram, G., 2003. An empirical analysis of follower entry timing decisions, Marketing Letters, 14 (3), 203-216.

Vohora, A., Wright, M., Lockett, A., 2004. Critical junctures in the development of university high-tech spinout companies, Research Policy, 33, 147-175.

Walter, A., Auer, M., Ritter, T., 2006. The impact of network capabilities and entrepreneurial orientation on university spin-off performance, Journal of Business Venturing 21 (4), 541-567.

Wright, M., Clarysse, B., Lockett, A., Binks, M., 2006. "University spin-out companies and venture capital", Research Policy 35 (4), 481-501.

Wright, M., Clarysse, B., Mustar, P., Lockett, A., 2007. Academic Entrepreneurship in Europe, Edward Elgar.

Wright, M., 2008. Investing in University Spin-offs. What Have We Learnt? What Is To Be Done? Presentation at the Connect Research Industry Conference, May $9^{\text {th }} 2008$, Rome.

Yin, R.K., 1991. Case Study Research. Design and Methods. Sage, Newbury Park.

Zangh, J., 2009, The performance of university spin-offs: an exploratory analysis using venture capital data, Journal of Technology Transfer (online first). 